\title{
A fenomenologia existencial de Heidegger e a crítica às ciências positivas
}

\section{The existential phenomenology of Heidegger and the criticism of positive sciences}

\author{
Katyana Martins Weyh \\ Graduanda em Licenciatura em Filosofia, Bolsista do Programa de Educação Tutorial - PET do curso de \\ Licenciatura em Filosofia, Universidade Estadual do Oeste do Paraná - UNIOESTE, Toledo, PR, Brasil.
}

Resumo: O tema da presente pesquisa é a análise do "fenômeno humano" na fenomenologia existencial de Heidegger; como tema subordinado a este primeiro, trataremos também da crítica heideggeriana às ciências positivas em suas abordagens do humano. Tal investigação se empenha em responder o problema: como Heidegger analisa o "fenômeno humano" em sua filosofia? Bem como ao subproblema, qual o teor das críticas que o filósofo volve às ciências naturais quando estas se ocupam de tal fenômeno humano? Assim, temos os objetivos de, primordialmente, indicar como Heidegger analisa o referido "objeto" a partir de sua filosofia e definir os termos da sua fenomenologia existencial.

Palavras-chave: Heidegger, fenomenologia, fenômeno humano, ciências positivas.

Abstract: The theme of this research is the "human phenomenon" in existential phenomenology of Heidegger. This research will also address the criticism of Heidegger to the positive sciences when it comes to human. This research seeks to respond to the problem: As Heidegger analyzes the "human phenomenon" in its existential philosophy? And also: How the philosopher criticizes the natural sciences that use the human phenomenon? So, our objective is to show how Heidegger analyzes the "object" from his philosophy and define the terms of their existential phenomenology.

Keywords: Heidegger, phenomenology, human phenomenon, positive sciences. 
Martin Heidegger teve como um dos principais objetivos em sua filosofia, analisar o fenômeno humano em face da recolocação da pergunta pelo sentido do ser, questão essa que conduziu sua mais renomada obra: Ser e tempo. Fez-se necessário elaborar uma ontologia fenomenológica e, para desenvolvê-la, Heidegger indica uma condição necessária para a recolocação da pergunta pelo sentido do ser, que é a análise do ente que pode compreender e questionar ser - analítica existencial. Em síntese, a analítica existencial é a análise do modo do ser-aí ser no mundo. Esta análise não deve ser entendida como decomposição (por analogia a química), pois constitui o ponto de partida e via de acesso à questão do ser.

Para Heidegger (2008), desde os gregos antigos, a questão pelo sentido do ser foi desprezada por esquecimento. O filósofo acredita que desde este período até a contemporaneidade não houve a distinção de ser e ente de forma adequada, pois existia certa "confusão" entre esses termos fundamentais no seio de toda a tradição metafísica. Na epígrafe de Ser e tempo, Heidegger escreve:

Pois é manifesto que estais de há muito familiarizados com o que pretendeis propriamente significar empregando a expressão 'ente', que outrora acreditávamos certamente entender mas que agora nos deixa perplexos. (HEIDEGGER, 2012, p. 31).

A partir disso e a fim de distinguir os termos "ente" e "ser-aí", a proposta de sua analítica existencial é tornar compreensível que o que chamamos de ôntico é relativo ao ente e o que se trata de ontológico é correspondente ao ser. Por isso, com sua ontologia fundamental, compreendemos que existem muitos modos de dizer o ente, dentre eles o ser-aí, que é um modo de ser de um ente privilegiado.

É este ente privilegiado que denominamos aqui como ser-aí, ente esse que tem sua especificidade no existir no mundo. Heidegger afirma que a "essência" desse ente está em sua existência, evidenciando que as características que se podem extrair deste ente não são qualidades, mas sim, modos possíveis de ser (HEIDEGGER, 2005). Isso mostra que o ser-aí é denominado como pura possibilidade e se determina como ente sempre a partir de uma possibilidade que ele é, e esse é o sentido formal de sua constituição existencial (HEIDEGGER, 1987). Essa questão do ser-aí como um ser de possibilidades se explica como um ser lançado para fora, ou seja, um ser aberto para as possibilidades do mundo, visto que as possibilidades são as determinações do ser-aí. Portanto, falar do ser-aí como experiência paradigmática do humano significa dizer que esse é um ente cuja essência consiste em "ex-sistir", pois o ser-aí é o único ente que é capaz de compreender sua própria existência, considerando que todo ser do ente possui alguma compreensão do seu sentido (HEIDEGGER, 2008).

Heidegger se interessou por estudar a questão do ser e em ter uma compreensão mais apurada sobre este assunto quando ainda era jovem e o fato de ter percebido que há um traço principal no modo de ser do fenômeno humano o levou a dar desdobramentos fundamentais a sua filosofia fenomenológica. Através de suas considerações, podemos entender que o que torna o homem um ente especial é o fato de existir, pois apenas assim pode ser conhecido e denominado como ser-no-mundo. Uma citação de Heidegger, em Seminários de Zollikon, deixa evidente o conceito e significado de ser-aí:

A palavra "Dasein (ser-aí)" significa comumente estar presente, existência [...] Em Ser e tempo, o aí $[D a]$ não significa uma definição de lugar para um ente, mas indica a abertura na qual o ente pode estar presente para o homem, inclusive ele mesmo para si (HEIDEGGER, 2009, p. 159).

Em vista disso, Heidegger propõe com a análise do ser-aí que a ontologia fundamental perceba os fenômenos como eles se mostram e aparecem, sem que haja a necessidade de uma ou várias explicações teóricas a seu respeito. Assim, abrindo mão da necessidade de teorizar os fenômenos humanos como foi feito desde a 
Grécia antiga. Embora pareça simples a forma de compreender o fenômeno humano proposto por Heidegger, de modo a tomar o ser-aí a partir de seu caráter de pura possibilidade de ser-no-mundo, há uma demasiada dificuldade em pensar dessa forma na contemporaneidade.

Isso acontece porque desde os primórdios da história da filosofia, se pensou o ser-aí como mera entidade, sem que fosse possível perceber quão importante é sua essência: o existir. $O$ fato de ter que utilizar da cientificidade para poder explicar o caráter específico do fenômeno humano é o alvo da crítica de Heidegger, uma vez que o ser-aí não é um ente que possa ser determinado pela ciência, pois sua única determinação possível é o caráter de poder-ser enquanto possibilidade de possibilidades no mundo (HEIDEGGER, 2008). Assim, Heidegger concorda com seu mestre Husserl quando este fala da psicologia moderna:

De acordo com Husserl, a psicologia moderna perdeu de vista a essência dos fenômenos psíquicos, uma vez que considerou esses fenômenos a partir de uma naturalização primordial. A psicologia moderna, ao tentar escapar da concepção tradicional da psicologia como uma ciência da alma, tomou os fenômenos psíquicos como se eles fossem localizáveis espácio-temporalmente e investigáveis segundo as leis causais e os princípios responsáveis pela sua determinação específica. Agindo assim, ela não percebeu em que medida uma tal naturalização repousava sobre uma cegueira em relação à essência propriamente dita de tais fenômenos. (CASANOVA, 2013, p. 42).

Fica claro, então, que o filósofo refuta o paradigma até então utilizado pelas ciências positivas, pois o fenômeno humano é mais do que mero haver, é mais do que ter um lugar e ocupar espaço no mundo, pois o existir pressupõe uma consciência dos entes e sobretudo, do ente que nós mesmos somos, tanto quanto da nossa existência no mundo, com as demais variadas formas de entidades (HEIDEGGER, 2008). Só o ser-aí existe e apenas ele é capaz de perguntar pelo seu ser. Por isso, ser-aí, para Heidegger, é o ser que se revela na própria existência, de tal modo que ele afirma que todas as coisas são (nesse caso, as "coisas" se tratam dos próprios entes), contudo, essas "coisas" não tem o caráter específico da existência. Devido a isso, Heidegger acredita que as ciências positivas não dão conta de descrever o fenômeno humano na sua totalidade enquanto um poder-ser possível, ou seja, tais ciências não fazem o exercício de uma analítica existencial.

Quando Heidegger afirma que apenas o ser-aí possui o privilégio ontológico de existir (KAHLMEYER-MERTENS, 2005), ele deixa evidente que o caráter de existência, que aqui é posto em questão só cabe ao ser do homem, pois ele é o único ser que compreende sua própria existência. Tal ideia fica evidente no texto Que é Metafísica? (HEIDEGGER, 1989), quando ele explica que o rochedo é, a árvore é, Deus é, mas somente o homem existe. Sendo assim, os entes simplesmente dados não possuem caráter de existência, mas o homem, sendo responsável pela sua peculiaridade enquanto um ser compreensivo e um ser de possibilidades, é o ser-aí que estabelece as ocupações no mundo em que existe.

Devido a isso, há a necessidade de compreender a indeterminação originária do ente que pode-ser. Por conta disso, considerando que o ser-aí (enquanto experiência consciente do humano) só é enquanto existe e enquanto tem consciência da sua existência, compreendemos que para além disso, ele é nada. Dizer que o ser-aí é nada, significa dizer que ele não tem uma determinação positiva, que ele é um poder-ser e que a existência é o lugar no qual ele realiza suas possibilidades (HEIDEGGER, 2008).

Quando Heidegger aponta que quando não existe, o indivíduo é nada, quer dizer que o nada é a ausência de determinação, porém é a presença total de possibilidade. Os fenômenos enquanto entes simplesmente dados estão no mundo, tanto quanto o ser-aí, porém, por serem fenômenos que nos aparece tal como são, apenas estão no mundo mas não existem nele. Não existem porque não são dotados de consciência, uma vez que, neste caso, consciência e existência são condições necessárias e 
indispensáveis ao ser-aí. Devido a isso, os entes fenomenais, aparecem e estão no mundo, enquanto o ser-aí aparece, está, existe e, sobretudo, tem consciência de que é o único capaz de questionar pelo seu sentido.

O nada do ser-aí é seu caráter de poder-ser, pois do mesmo modo que aponta para a possibilidade de realizações do ser-aí, aponta para sua negatividade. Por isso dizemos que o fenômeno humano traz a marca do possível e esse possível se expressa na sua própria existência. Desse modo, a ontologia fundamental heideggeriana é o projeto principal de Ser e Tempo, por tratar da questão da busca pelo sentido do ser. Portanto, a analítica existencial é o subprojeto que descreve e analisa fenomenologicamente o ser-aí, este que não é algo simplesmente dado, por em sua origem ser um ente de possibilidades. Assim, compreendemos que o ser-aí não possui traços característicos (determinação), pois é apenas um ser histórico em face do tempo. O fato de ser um ente de possibilidades se dá por ser um ente que pensa e que compreende os múltiplos modos do ente se mostrar e principalmente tem compreensão de que ele (ser-aí) é o único ente capaz de perguntar pelo seu sentido.

Em vista disso, levando em conta o projeto da ontologia fundamental proposto por Heidegger, é notório que houve motivos que o fizeram ter a necessidade de pensar o ser-aí de forma bastante específica, forma esta que se distancia drasticamente do modo como a modernidade e as ciências positivas compreender o homem. Leo Strauss acredita que a fenomenologia existencial de Heidegger se contrapõe ao positivismo que domina a intelectualidade moderna, pois "O positivismo é o ponto de vista filosófico segundo o qual o único saber verdadeiro é o científico" (AINBINDER, 2008, p. 12, tradução nossa). Assim, Heidegger nos mostra que as ciências positivas analisam e explicam o fenômeno humano apenas em suas características ônticas, o que fez a modernidade não dar o devido valor a importância da questão do ser.

Além disso, o filósofo acertadamente faz uma diferenciação entre o que vem a ser sua ontologia fundamental e o que são as ciências positivas. Quando se refere à ontologia fundamental, Heidegger fala a respeito do questionamento pelo sentido do ser, enquanto que as ciências positivas falam sobre a investigação do ente. Sendo assim, remetemos a diferenciação já apontada em nosso texto, a respeito de ôntico e ontológico, onde, nesse caso, ôntico é relativo à investigação das ciências positivas e ontológico é referente à questão primordial do projeto heideggeriano: a pergunta pelo sentido do ser.

Contudo, Heidegger não teve a pretensão de negar o conhecimento das ciências positivas, no entanto, critica a forma como tais ciências bordam o humano, pois os cientistas tem um olhar voltado aos resultados objetivos de suas pesquisas e análises, o que dificulta e quase impossibilita que se atentem de fato para o ser do ente que investigam. Essas ciências que tematizam o homem, tais como a biologia, a psicologia, a antropologia, etc., não respondem de forma precisa a questão do modo de ser do ente que nós mesmos somos e isso Heidegger deixa claro em Ser e tempo:

A questão crítica não pode, contudo, se deter aqui. O que está em questão é o ser do homem todo, que se costuma apreender como unidade de corpo-alma-espírito. Por sua parte, corpo, alma, espírito, podem designar âmbitos de fenômenos que, no propósito de determinadas investigações, podem ser tematicamente separados; dentro de certos limites, sua indeterminação ontológica pode não ter muito peso. Mas na pergunta pelo ser do homem, o ser não pode ser calculado pela soma de modos-de-ser do corpo, da alma e do espírito que de resto ainda teriam de ser determinados (HEIDEGGER, 2012, p. 157).

É nesse sentido que Heidegger tem uma opinião crítica frente às ciências positivas, uma vez que ela lida com os entes apenas no domínio ôntico, deixando a desejar, por exemplo, quando aborda o fenômeno humano como um ente determinado positivamente. Ademais, a preocupação de Heidegger é com a forma como as ciências positivas analisam o ser-aí, tomando-o como um ente simplesmente presente, um ente determinado, assim, concebendo o fenômeno humano como se estivessem analisando 
um ente qualquer, passível de comprovação, determinação e alvo de experimentação científica. É nesse sentido que, como aludimos acima, a especificidade do ser-aí, que é sua existência, e a sua essência que é a possibilidade de ser-no-mundo, ficam negligenciadas e desprezadas por esquecimento.

Todavia, há de se ter em mente que Heidegger, embora critique as ciências positivas, não pretende superar a história da metafísica de forma a abandonar ou recusar os fatos antecedentes. Ele mesmo reconhece que "seria um grande equívoco pensar que sempre poderíamos conformar a filosofia a partir de uma recusa completa da tradição histórica" (HEIDEGGER, 1987, p. 5). Assim, tendo em vista que Heidegger se preocupa e tenta dar um desdobramento diferente da tradição filosófica para a questão do esquecimento do ser, a recolocação da pergunta pelo seu sentido se faz, sem dúvidas, necessária. Com a analítica existencial, Heidegger busca esclarecer a questão que diz respeito à diferença de ser e ente, a fim de revelar o problema fundamental de sua ontologia: a especificidade do ser-aí. Dessa forma, é possível a caracterização do fenômeno humano em sua fenomenologia existencial.

Em vista dos argumentos apresentados, descobrimos que Heidegger se propõe a compreender questões de grande importância para a história da filosofia, principalmente da ontologia e que, mais tarde, serviu muito de base para não apenas amparar a psicologia empírica quanto para criar uma psicologia clínica com bases fenomenológico-existenciais (HEIDEGGER, 2009). Além disso, compreendemos que o filósofo denomina o fenômeno humano e sua singularidade, bem como entende que o ser-aí é um ente especial, que existe enquanto um ser de possibilidades.

Em suma, vimos que a existência se constitui como caráter necessário e imprescindível para a compreensão do ser-aí e investigamos a caracterização deste ente especial no campo da fenomenologia, bem como mostra a crítica de Heidegger às ciências positivas, por se ocuparem do fenômeno humano de modo radicalmente diverso de sua ontologia fundamental. Desse modo, percebemos que a fenomenologia existencial heideggeriana confronta, assim, os métodos com os quais as referidas ciências abordam o humano. Com isso, é notório que Heidegger se tornou um filósofo de destaque na área de ciências humanas, principalmente na filosofia e na psicologia.

Correspondência: Katyana Martins Weyh. Universidade Estadual do Oeste do Paraná - UNIOESTE, Campus Toledo, Rua da Faculdade, 2550, CEP 85903-000, Toledo, PR, Brasil. E-mail: katian.na@hotmail.com Conflito de interesses: Nenhum.

Todos os autores leram e aprovam a versão final submetida a revista Em curso. 


\section{Bibliografia}

AINBINDER, B. Sobre Heidegger: cinco voces judías. Buenos Aires: Manantinal, 2008.

CASANOVA, M. A. Compreender Heidegger. 4a. ed. Petrópolis: Editora Vozes, 2013.

HEIDEGGER, M. Introdução à Metafísica. Tradução de Emmanuel Carneiro Leão. Rio de Janeiro: Tempo Brasileiro, 1987.

HEIDEGGER, M. Que é metafisica? Tradução de Ernildo Stein. São Paulo: Abril Cultural, 1989. (Os Pensadores).

HEIDEGGER, M. Carta sobre o humanismo. Tradução de Rubens Eduardo Frias. São Paulo: Centauro, 2005. HEIDEGGER, M. Ser e tempo. Tradução de Márcia Sá Cavalcanti. Petrópolis: Vozes, 2008.

HEIDEGGER, M. Seminários de Zollikon. Editado por Medard Boss. Tradução de Gabriela Arnhold e Maria de Fátima Almeida Prado. 2a. ed. Petrópolis: Vozes; Bragança Paulista: Editora Universitária São Francisco, 2009.

HEIDEGGER, M. Ser e tempo. Tradução de Fausto Castilho. Campinas: Editora Unicamp; Petrópolis: Editora Vozes, 2012.

KAHLMEYER-MERTENS, R. S. Filosofia primeira: estudos sobre Heidegger e outros autores. Rio de Janeiro: Papel Virtual, 2005. 